\title{
O xadrez da organização do espaço: o jogo do(s) plano(s) no território do município
}

\author{
Exzolvildres Queiroz Neto* \\ Karoline Ribeiro** \\ Luciane Vargas ${ }^{* * * *}$
}

Resumo

O presente trabalho é resultado de um processo de revisão bibliográfica envolvendo referenciais teórico-conceituais do planejamento urbano e regional, organização do espaço e do território para uma pesquisa do uso e ocupação do solo na interface periurbana de Foz do Iguaçu, PR, que se iniciou em 2012 e foi concluída em 2014. A bibliografia analisada corresponde ao final dos anos de 1970 até os anos 2000 cujos trabalhos descortinam o processo de transição conceitual, pós-ditadura militar no Brasil, prenunciando a busca por uma abordagem mais democrática e crítica em relação ao território. $\mathrm{O}$ eixo da análise tem por objeto a concepção de uma cidadania territorial que foi preconizada pela Constituição de 1988, subsidiária do Estatuto da Cidade e, consequentemente, de sua ferramenta de planejamento, o plano diretor. É possível identificar um jogo de ações e tomadas de decisões contraditórias na composição do território do município. $\mathrm{O}$ artigo no formato de um ensaio visa contribuir para a análise teórica ao demonstrar as variáveis políticas, sociais, espaciais, metodológicas e econômicas que se inter-relacionam a partir do espaço e expõem a complexidade do território do município ao tratarmos do planejamento e da gestão pública. O texto será composto pela introdução, o marco teórico-conceitual, em que é estruturada a filigrana do problema da organização do espaço, e por fim as considerações finais.

Palauras-chave: Organização do espaço. Planejamento do território. Ordenamento territorial. Escalas espaciais.

* Doutor em Engenharia Agrícola - Planejamento e desenvolvimento rural sustentável - pela Universidade Católica de Pernambuco. Professor adjunto II no Instituto de Economia, Sociedade e Política de Desenvolvimento Rural, Universidade Federal da Integração Latino-Americana. E-mail: queiroz. neto@unila.edu.br

** Bacharel em Desenvolvimento Rural e Segurança Alimentar na Universidade Federal da Integração Latino-Americana. Bolsista de iniciação científica pela Fundação Araucária 2012-2013. E-mail: karoline.ribeiro@unila.edu.br

*** Discente do bacharelado em Desenvolvimento Rural e Segurança Alimentar na Universidade Federal da Integração Latino-Americana. Voluntária na iniciação científica 2012-2013. E-mail: luciane. vargas@unila.edu.br

http://dx.doi.org/10.5335/rtee.v22i46.6752

Submissão: 24/04/2015. Aceite: 14/11/2015. 


\section{Introdução}

Características de arte e ciência são encontradas nas composições enxadrísticas que abrange aberturas, meio-jogo e as fases que subdividem o transcorrer do jogo. O xadrez, por ser um jogo de estratégia e tática, não envolve o elemento sorte. A única exceção é o sorteio das cores no início do jogo, já que as brancas sempre fazem o primeiro movimento e teriam, em tese, uma pequena vantagem por isso. Essa teoria é suportada por um grande número de estatísticas embora alguns especialistas não aceitem a existência de tal vantagem.

O xadrez da organização do espaço é um jogo de múltiplas variáveis que se estabelece no território do município, são múltiplas linguagens, paisagens, objetos, ações, visões de mundo, elementos materiais, imateriais e simbólicos. Por se tratar de um espaço racional (concepção mais ampla) o município é alvo de várias estratégias e territorializações. $\mathrm{O}$ desenho desse jogo de poder no território não manteve as regras totalmente rígidas ao longo da história, mas é verdade que a cidade (conceito fluido para além do urbano) produz a si mesma, mas deve ser considerada uma produção composta de múltiplos saberes. Desde o século XIX há uma tendência, a partir do Ocidente, de homogeneização dos usos do território instituída pela lógica urbano-industrial, o que pressionou o espaço rural, gerando espaços complexos como a interface periurbana, na qual coexistem múltiplos usos e ações.

A cidade moderna é o tabuleiro das perspectivas cartesianas de se pensar o espaço. A efetivação da estrutura econômica, com vistas ao controle, suplanta o cotidiano, os contextos. A lógica funcionalista e mecanicista dita o ritmo da razão, da emoção e do tempo. Ocorreu a separação, impossível, do tempo e do espaço, isto é, da história cotidiana. O espaço em seu arcabouço de complexidade foi relegado à dimensão física da paisagem, um problema que aprisiona tanto o urbano quanto o rural.

Assim, a cidade, em si, ganha dimensão própria para além do urbano e do próprio território do município como processo. Portanto, de múltiplos "espaços vividos" movimentamo-nos em direção à unicidade da técnica que abrange a construção, os processos, a circulação, a forma, o conteúdo, as estruturas, as funções, as ações, as escalas e, às vezes, as reflexões. É bem verdade que os múltiplos contextos desnudam essa unicidade e deixam fluir as possibilidades do território do município, onde o planejamento contextualizado pode produzir as regras de um jogo mais próximo da realidade do uso e ocupação do solo no cotidiano. No decorrer do texto, conceitos como cidade, território, planejamento urbano e espaço periurbano serão trabalhados de forma a desenhar os aspectos do jogo do uso do território do município. 


\section{O xadrez da organização do espaço: o jogo a partir da cidade}

O espaço e o tempo são indissociáveis, mas se conflagram no "xadrez da organização do espaço". Há uma pretensa sobreposição do tempo, em relação ao espaço, no jogo dos diversos interesses. Ora, a quem interessa o "avanço" do tempo configurado pela circulação e pela aceleração do crescimento econômico? No arcabouço da modernidade, o espaço foi apropriado como fixo e o tempo (história) se consubstanciou em fluxos, principalmente econômicos, que geraram profundas mudanças. Esse equívoco superestima o fluxo. Assim, o espaço é tomado parcialmente (alienação espacial) o que contraria as análises de Santos (2002), que admite a construção social do espaço composta de fixos e fluxos. Por ser uma construção social, a cidade (e o espaço urbano) é complexa, efêmera, transitória, mutante, duradoura em sua essência. Assim, o espaço urbano, na contemporaneidade (que pode ocorrer, também, no espaço rural), é um jogo do uso dos recursos comuns no espaço-tempo da cidade, não necessariamente do município, um paradoxo da própria noção de sustentabilidade do território do município.

Para Harvey (1995), a queda das barreiras espaciais reforçou, paradoxalmente, o significado do que o espaço contém. Conforme Castells e Borja (1996), as redes não prescindem do lugar (para além da noção de localização), ao contrário da lógica econômica predominante. De acordo com Vainer (2001-2/2002-1), os processos que transformam o debate urbano em questões de produtividade e competitividade nada mais são do que o "afunilamento" das técnicas para imprimir a unicidade com vistas à derrubada das barreiras (sentido amplo) e, assim, aumentar os ganhos e se valer dos fluxos internacionais. Evidentemente, a civilização humana não prescinde do espaço, mas as ações e suas lógicas anseiam por libertar-se do lugar.

A cidade produz informações sobre si mesma (instituições públicas e privadas, universidade, cinema, literatura, arte, linguagens), o que pode deixar de lado o espaço rural e a composição do território municipal para o planejamento. Arantes (1996) argumenta que a construção do discurso, sobre a cidade, enreda-se nos planos teóricos e práticos das intervenções urbanas. A autora verifica que a abordagem sobre a cidade é uma construção do domínio da racionalidade [instrumental, na nossa perspectiva], funcionalidade, eficiência e ordenação das funções pretensamente em nome da sociedade. Sobre a cidade predomina a representação simbólica do princípio máximo da flexibilidade e o design de microespaços que desloca o ângulo regional do município. 
Obviamente esses eventos, ao repercutirem no território do município, impõem à cidade, em sua diversidade de representações, um palco privilegiado para o amálgama de múltiplos e simultâneos processos, funções, formas, estruturas, conteúdos e ações. A cidade, é bom frisar, permite a articulação entre os diversos atores sociais e setores econômicos de forma transescalar.

\section{A dimensão escalar do planejamento do território}

Vainer (2001-2/2002-1) trabalha o conceito de escala para além da dimensão espacial no que tange ás medidas. A escala é fundamental para a compreensão do espaço, portanto do tempo, mas deve ser entendida com base na inter-relação das diversas variáveis econômicas, sociais, políticas, históricas, culturais e ambientais. Qualquer escala entre o local e o global admite, diacronicamente, os diferentes níveis e cada um apresenta variáveis que se alternam em múltiplas dimensões. Portanto, conceituar a escala é relativamente simples, quando se tem em mente a dimensão da proporcionalidade, mas torna-se complexo ao admitirmos a dimensão da inter-relação dos fatos e suas variáveis no espaço geográfico. $\mathrm{O}$ território do município se consubstancia na inter-relação dos elementos do espaço do lugar, mas o que é a escala do lugar? Seria o contexto? Como traduzir o contexto em suas multiplicidades e complexidades? O contexto é representado pela história (tempo) uma construção social. Há uma tendência para admitirmos o planejamento como um elemento de ordenamento da espontaneidade dos contextos de cada lugar.

Na concepção de Castells e Borja (1996), as cidades somente se tornarão protagonistas se forem, devidamente, dotadas de um planejamento estratégico (para enfrentar a globalização). Nesse jogo de estratégias, o planejamento é uma epistemologia, uma metodologia ou uma função? Podemos alegar que o planejador se mimetiza, cada vez mais, com o seu "tradicional adversário" o empreendedor? Seja como for, a gestão e o planejamento do território, para além das questões teóricas, é uma temática que envolve a percepção de uma realidade mais imediata e a representação de um contexto que está em constante transformação admitindo os diversos níveis de escala.

Planejar traz em si a dimensão do pensar, da ação-reflexão, tal processo ocorre no espaço-tempo do território. Contudo, são múltiplos territórios com seus recursos passíveis de apropriações no município, mas como ter acesso à regra do jogo dos bens, serviços públicos e recursos do território? 


\section{$4 \mathrm{O}$ problema do acesso e dos usos dos recursos do território}

O cerne do diálogo epistemológico, nesta seção, será estabelecido com Ostrom et al (1990), cujo arcabouço teórico é nutrido por uma análise institucional acerca do uso dos recursos comuns (QUEIROZ NETO, 2011). A governança do espaço municipal traz em si o dilema da apropriação dos recursos a partir do uso do território.

$\mathrm{Na}$ territorialidade municipal, os valores individuais diferem da percepção de quão fácil ou oneroso é a exclusão ou limitação dos potenciais utilizadores dos recursos comuns uma vez que são movidos pelas ações do outro indivíduo. A ação deve ser entendida a partir das considerações de Giddens (1987), em que a ação não se remete somente ás intenções, mas à capacidade do ator social em fazê-las. $O$ ator social não são apenas os indivíduos, mas comunidades, instituições públicas e privadas, empresas, organizações e associações. Trata-se, todavia, de ações racionais, mas não de uma única racionalidade, por exemplo, a instrumental econômica, mas de múltiplas racionalidades desempenhadas pelos atores sociais. Logo, são entidades capazes de tomar decisão em determinado contexto de um território. Isso quer dizer que não devemos categorizar algumas ações como irracionais, pois, como alega Veiga, "não podemos mesmo dizer que uma acção de um actor é irracional, mas apenas que ele poderia ter agido de outra forma se dispusesse de outras informações, outros meios e circunstâncias exteriores". Ainda, segundo o autor, a parte que "não depende do ator social" ou que não está sob o seu "controle" remete ao conceito de estrutura" (2005, p. 47).

Em Giddens (1987), o termo estrutura ou estrutural define-se como: uma inter-relação de regras (normas, significados) e recursos (alocação e autoridade) inseridos na reprodução social. Para o mesmo autor, as estruturas são conjuntos de regras e recursos isoláveis no espaço-tempo de cada sistema social a partir das práticas sociais.

Uma dimensão fundamental para compreendermos as ações humanas é o conceito de território. Contudo, não devemos tratar o território como um ator social. O território é construído e desconstruído a partir das ações o que demanda uma correlação com o tempo; a história. O território, com seus recursos (sentido amplo), deve ser entendido fundamentalmente como a instância das relações de poder envolvendo os atores sociais e a possibilidade de múltiplas e simultâneas funções, lugares contíguos, dispersos e lugares em rede (SANTOS, 2002). Por conseguinte, a territorialidade é a manifestação das assimetrias geradas pelas relações de poder. Nesse sentido, o território envolve uma noção de escala e deve ser compreendido a 
partir das inter-relações que ocorrem no espaço. O território é a soma e a representação das diversas funções, conteúdos, formas, processos, estruturas e ações que se engendram no espaço, no lugar.

Os recursos comuns, que transitam entre as dimensões públicas e privadas, apresentam a prerrogativa do fluxo. O fluxo pressupõe dinâmica, concomitantemente, contenção, inércia, fluidez, instabilidade, incerteza e irreversibilidade do tempo. Por ser dinâmico, suplanta as fronteiras, gerando uma perspectiva de múltiplas territorialidades em um mesmo território. Portanto, os problemas advindos da utilização dos recursos comuns podem ser analisados pelo ângulo da sustentabilidade, isto é, a capacidade de criação de um recurso e a capacidade de evitar a sua destruição.

Assim, a conceituação teórica deve ser lastreada pelo contexto. O conceito de lugar torna-se fundamental, nesta análise, mas é necessário ressaltar que, o processo que explica o lugar, somente faz sentido em conexão com as diversas escalas (regional, nacional, internacional) e suas variáveis. Não é possível explicar o lugar por ele mesmo, mas pelas inter-relações. A percepção das inter-relações dos fatos de uma realidade está relacionada à forma de perceber os fatos em uma dada realidade, na qual se inter-relacionam os atores sociais.

$\mathrm{Na}$ contemporaneidade, os espaços urbanos ou rurais, sujeitos aos múltiplos arranjos produtivos e de organização socioespacial do uso do solo, devem ser considerados a partir da interação dos processos locais de produção, consumo, dos significados sempre contextualizados e abertos aos fluxos ao longo do tempo.

Considerando o território municipal e suas parcelas urbanas ou rurais disponíveis para uso do solo (considerado um recurso), cada ator social deve decidir como usar essas áreas (o fator escala é fundamental). Assim, em parte, cada uma das decisões vai refletir as opções mais gerais e os usos que cada ator social faz das informações e conhecimentos (influências internas e externas), em função de um "mercado", da satisfação do bem-estar, das ações do Estado com vistas ao ordenamento territorial, das questões ambientais, além das decisões de outros atores sociais em relação às suas áreas e as influências das políticas públicas mais amplas.

Johnston (1986), citado por Queiroz Neto (2011), afirma que a maneira pela qual os atores sociais (pesquisadores, agências de fomento, instituições públicas, privadas e moradores de um determinado lugar) percebem os "problemas" e os "recursos" dos territórios desempenha um papel significativo em suas decisões no que se refere ao gerenciamento desses recursos e na tomada de decisão. Devemos considerar que os atores sociais apresentam comportamento racional (múltiplas racionalidades) na organização de suas preferências, que as ações produzem 
complexidade sendo impossível para qualquer ator social, analista, cidadão ou organização deter todas as informações.

Para tentar prever como os atores sociais irão se comportar devemos considerar, pelo menos, quatro variáveis: 1) Os tipos de ações e os potenciais resultados. Devemos considerar que as ações são racionais e dotadas de propósitos, mas podem ser aleatórias, triviais ou reflexivas. As ações podem conduzir a comportamentos e respostas estereotipadas. 2) Considerar a forma como os atores sociais se capacitam no processo, suas contingências, conhecimento e utilização das informações. 3) Analisar e avaliar os critérios utilizados por cada um para decidir sobre um determinado curso da ação. Cada decisão é estabelecida com base no conhecimento. Entretanto, somente em situações excepcionais pode um tomador de decisões apropriar, analisar e interpretar todas as informações de um ambiente. 4) Há diversos processos, variáveis e recursos que podem conduzir os envolvidos a uma determinada situação. A informação é avaliada, por cada ator social, de acordo com critérios preestabelecidos. As escolhas habituais são estabelecidas a partir de referenciais anteriores, mas as refletidas ocorrem a partir da ponderação das informações de um contexto e das variáveis socioespaciais e socioambientais.

Contudo, não é possível a um único tomador de decisão evitar ações subótimas no uso dos bens e recursos do território. Ações subótimas podem desconsiderar os contextos e o ambiente institucional gerando a exclusão de um potencial ator social.

Logo um dos problemas na análise dos recursos (sentido amplo), em um determinado contexto municipal, é a capacidade de entender a contabilidade do uso de um recurso, isto é, a apropriação eficiente exige soluções para o melhor momento e local. O território é um sistema aberto e sensível aos fluxos (circulação, comunicação, informação, comercialização) o que nos conduz ao conceito de externalidade: a interdependência entre os sistemas e subsistemas. As externalidades produzem efeitos complementares e substitutos. Os efeitos complementares podem ser vislumbrados positivamente e os substitutos podem exercer, temporariamente, a função de um efeito complementar gerando a entropia do sistema. Portanto, a externalidade dever ser devidamente contabilizada ou pode gerar uma alocação subótima.

Deve ser ressaltado que não há uma distribuição homogênea dos recursos no território. Todavia, a possibilidade de avaliar a realidade (configuração espacial do território) é momentânea em um contexto sócio-espacial dinâmico e mutável. Por vezes, pode ocorrer uma leitura territorial incompleta. Por isso, uma perspectiva territorial na interface sócio-econômica e ambiental gera subsídios para o planejamento e gestão de políticas públicas voltadas para o desenvolvimento. Podem ocorrer equívocos em relação ao espaço municipal envolvendo aspectos técnicos, 
históricos, culturais e simbólicos quando vinculamos a dimensão do Estado (nos diversos níveis) e as limitações da gestão pública, os interesses do mercado e as reais demandas da sociedade.

As limitações das ações da gestão pública no território podem ser definidas a partir das análises de Queiroz Neto (2011): a) problema de linguagem - pensamento - estrutura do que se propõe de alternativas, viabilidades técnicas, econômicas e de quem é percebido como receptor; b) momento histórico havendo ou não transformações da estrutura, dos processos, das formas, conteúdos, funções, reflexões e ações. O momento histórico é, concomitantemente, um momento espacial, pois, há inter-relações dos fatores da realidade, c) cultura - antagonismos entre a cultura técnico-científica, econômica, política e a cultura cotidiana e contextualizada do espaço municipal; d) níveis de percepção das inter-relações dos fatos e eventos no espaço.

A ação humana sobre o espaço, embora muitas vezes perceptível a olho nu quanto a seus efeitos, é difícil de ser avaliada quanto às suas causas específicas e, sobretudo, quanto à intensidade e frequência de atuação dos processos resultantes, isto é, a quantificação, qualidade dos dados e o monitoramento dos seus efeitos. Os maiores problemas residem no acompanhamento da influência de cada tipo de uso do solo no desencadeamento de um processo cujos efeitos resultam da soma de várias ações humanas. É o caso também da avaliação do fator tempo, raramente existem registros fiéis da cronologia relativa à implantação dos diversos tipos de uso e ocupação do solo bem como dos impactos ambientais, tecnológicos e inovadores. Assim, a quantificação e o monitoramento de todas as variáveis envolvidas no espaço, no desencadeamento e na evolução do uso da terra, se, por um lado, é desejável e útil, por outro, esbarra na falta de recursos dos agentes públicos e privados.

Ademais, o dinamismo da ocupação do solo, por exemplo, é acompanhado por mudanças igualmente rápidas nas características ambientais de sustentabilidade exigindo agilidade na solução dos problemas gerados ou da informação de ações bem-sucedidas, principalmente, na escala do lugar. O acesso aos bens e recursos públicos e aos usos, que são feitos dos mesmos, constituem a base dos dramas humanos, no espaço municipal brasileiro, gerados pelo discurso da eficiência tendo como referencial a maximização dos lucros ancorados, via de regra, no mercado imobiliário.

No cerne dessa discussão, está o tema do desenvolvimento um conceito (ou crença) amálgama de vários elementos teóricos, quanto de políticas públicas, além da própria inserção no contexto capitalista de parcela da população de excluídos. É um processo de equilíbrio dinâmico, das variáveis envolvidas, em termos de 
planejamento e de gestão das interações que se processam entre as variabilidades econômicas e sociais, por um lado e as variabilidades naturais (os riscos ambientais), por outro - tanto no espaço quanto no tempo. O planejamento com vistas ao desenvolvimento, normalmente, é estruturado a partir do espaço urbano - especialmente a cidade - mas deveria considerar o território do município.

\section{Considerando a (im)possibilidade do planejamento do território no município para além da noção de cidade}

Maricato (2000) argumenta sobre o predomínio de planos (excesso de normas e concepções a priori) de governo, em detrimento dos planos de Estado (políticas institucionais), que são descontextualizados, pois, há um recorrente desconhecimento da realidade sociocultural e socioespacial. Segundo, a autora, persiste a reincidente ausência de planos de ação, cujas intenções se materializem no tempo e no espaço. Assim, as constatações de Maricato (2000) levantam a hipótese de uma crise das matrizes espaciais: a) modernista/funcionalista; b) do Estado racional e keynesiano; c) da relação público/privado; d) do plano do discurso (matriz postiça da viabilidade - mudanças de denominações dos planos visando à fuga do desprestígio); e) da produção massiva de cidade (fordismo). O problema do uso e ocupação do solo é o pano de fundo das estratégias de organização do espaço. O cerne do problema no Brasil é a estrutura fundiária calcada mais no valor da terra, em si que na função social. Diversos autores constatam o problema do ordenamento urbano a partir da estrutura fundiária brasileira, normalmente, excludente e espoliadora (COSTA, 1988; MARICATO, 1994; MARICATO, 2000; MONTE-MÓR, 1994; CARDOSO, 1997).

No processo de (re)democratização do Brasil, para além de uma concepção ideológica quando se trata das demandas do espaço urbano, surge o "espaço mítico" das deliberações envolvendo o planejamento urbano a partir dos planos diretores que se multiplicaram pelo vasto território nacional desde o Estatuto da Cidade (BRASIL, 2001), e podemos cogitar a acerca de uma "indústria do ordenamento territorial”. Logo, pela perspectiva da gestão, poderia ser uma constatação alvissareira se não fossem os desencontros entre as concepções, elaborações, metodologias, compreensões, implementações dos planos e a realidade.

O plano diretor (BRASIL, 2001) não rompe, na maioria dos lugares, com as matrizes espaciais decadentes e às vezes reifica um pretenso plano de ação democrático. No caso brasileiro, as matrizes envolvem, aqui de forma sucinta, o espaço, a teoria, a legislação, a tributação, os diversos tipos de uso, o planejamento, a 
gestão e a tênue relação democracia/cidadania. Logo que discurso, sobre o planejamento e a gestão, envolvendo o território do município, deve ser apropriado na contemporaneidade?

Conforme Arantes (1996), embasado nas influências, o ideário da gestão eficiente, fala-se menos em planejamento e mais em requalificação ao transitar do domínio da técnica para o vasto domínio do cultural. Assim, tudo virou cultura e tudo é passível de associações simbólicas. São produzidas odes ao contextualismo de variadas combinações e conotações: existencialismo e estruturalismo, linguística, antropologia e historicismos de tinturas marxistas e revivalistas. Nesses termos, Arantes (1996) aproxima-se das análises de Harvey ao discorrer sobre o pós-modernismo e constatar o cultivo de um "[...] conceito do tecido urbano como algo necessariamente fragmentado, um 'palimpsesto' de formas passadas superpostas umas às outras e uma 'colagem' de usos correntes muitos dos quais podem ser efêmeros" (1991, p. 70). Desponta nas análises dos autores uma recorrente ambiguidade contextualista sobre o espaço urbano a partir do exercício da diferença cultural. Desenha-se o suposto amálgama de diferentes culturas, mas que, no fundo, se consubstancia em uma funcionalidade cultural. A cidade em meio à ambiguidade que se descortina pelo espaço, onde os sítios específicos da cidade moderna são transformados em espaços liminares pós-modernos que tanto falseiam como fazem a mediação entre natureza e artefato, uso público e valor privado, mercado global e lugar específico.

A terra no Brasil é o elemento amálgama do processo de produção do espaço pelo viés da propriedade excludente que, remonta ao período colonial transitando pelo Império, a República e resistiu à democratização a partir da Constituição de 1988, que abriu caminhos às demandas dos movimentos sociais. Formou-se no Brasil um mercado de terra transacionável aos moldes dos ativos financeiros. Assim, tanto o setor público (investimento em infraestrutura, construção de moradias), quanto o privado (incorporações e loteamentos) geram novas demandas por bens e serviços públicos independente da função social da terra. Nesse sentido, Costa (1997) alega que há uma tendência de se trabalhar a partir de uma contraditória perspectiva espacial, isto é, o espaço como continente uma forma sem conteúdo socialmente produzido com base em simples reflexões das relações sociais de produção. Muito diferente de uma análise socioespacial, que considera a produção social do espaço e todas as variáveis que, advém desse processo.

Choay (1979), por sua vez, chama a atenção para as duas vertentes predominantes sobre o espaço: 1) culturalista e 2) progressista/racionalista que tem maior repercussão no caso brasileiro. Assim, no processo de planejamento, a análise 
socioespacial é substituída pela imposição da ideia de progresso, o que, teoricamente, justificaria a prática de planejamento e gestão descontextualizada, portanto, sem a práxis. O território do município configurou-se, e se configura, como o embate entre o público e o privado. De um lado, o Estado e a sua burocracia impregnada de agentes que visam, em muitos casos, aos interesses particulares, e o setor privado, que reforça, via discurso da propriedade, a necessidade de expansão da demanda descolada da totalidade. Logo, são parcelas do solo que, a partir da demanda, caracterizam-se em falsas configurações do território, pois, não há uma interação com o todo do município.

Camargo (1976) e Kowarick (1979) chamam a atenção para a importância do papel do Estado na regra do jogo dos planos e a sua possível omissão quanto à dimensão espacial do município. De fato, a tensão entre público (coletivo) e privado parece ser, momentaneamente, resolvida, quando o cidadão vislumbra a propriedade (lote, casa, apartamento, terreno) como uma forma de fazer parte da cidade. Destarte, o acesso ao solo faz-se via propriedade, o que poderia explicar a "omissão" do Estado, por um lado, e a "lógica da desordem", a partir dos interesses do capital imobiliário (CAMARGO, 1976; CAMPOS, 1989).

Há no planejamento territorial, seja urbano ou rural, certo cortejar com a ideia de ordenamento. O que faz lembrar Baudrillard (1991), ao analisar a fábula de Borges sobre um dado império, no qual os cartógrafos desenhavam, minuciosamente, um mapa que acabava por encobrir o próprio território. Qual a relação? No Brasil a ordenação territorial antecede o próprio território por meio de uma miríade de legislações e normas que suplantam o plano, isto é, o planejamento é relegado ao esquecimento em prol das normas (burocracia taylorista e dos tipos ideais weberianos) que, na maioria dos casos, não encontra abrigo na realidade.

Para Monte-Mór (2007), o arcabouço político-institucional do planejamento evidencia o descompasso entre o ambiente institucional e a vida real no território. Fica claro que o autoritarismo do período militar, antes de ser uma novidade no Brasil, rompeu o diálogo da práxis (ação política) entre os diversos atores institucionais e a sociedade. O que parece temeroso, entretanto, não é reconhecer as mazelas de um planejamento autoritário, mas conviver com uma frágil democracia territorial.

Entretanto, há perspectivas que se vislumbram na contemporaneidade, uma vez que o "espaço vivido" traz ao território novos problemas e questões, mesmo que sejam "novas-velhas questões" retrabalhadas que denotam certa insatisfação com a falta de um plano, pior, de um plano de ação nas diversas escalas: municipal, estadual e federal. 
O debate, pós-ditadura militar, sobre o planejamento e a gestão públicos no Brasil pode ser compreendido da seguinte forma: a) o movimento em prol da reforma urbana no período da redemocratização do país; b) o reconhecimento do status de política pública do plano diretor após a aprovação do Estatuto da Cidade; c) o planejamento estratégico como discurso da eficiência com base em objetivos centrados no conceito do Estado-mínimo sob os auspícios do neoliberalismo.

Pela via institucional, é mais barato regulamentar do que monitorar a informação nos locais mais susceptíveis ao risco, por exemplo. A rubrica territorial do desenvolvimento sustentável traduz, concomitantemente, os anseios de instituições e da população que oscila das constatações empíricas, os limites do discurso, e a necessidade de se sentir participativa de algum modo. Na contemporaneidade, tendo em vista a complexidade da vida humana, há um discurso uníssono, nos diversos setores da sociedade, pela conciliação com a agenda ambiental que pode gerar novos parâmetros sistêmicos. Esses setores envolvem o consumo, o modo de vida, a ciência, o saber local, entre outros que formam o arcabouço dos processos do sistema sociedade-ambiente e expõem as contradições do modelo urbano-industrial implementado no Brasil.

O contexto dos anos 1980, na irrupção dos debates sobre a reforma urbana com participação dos movimentos sociais, a ação coletiva gradualmente cede espaço à institucionalização das regras do jogo pautado pelo discurso da propriedade. Entretanto, com advento do conceito de plano diretor, emergem dos resquícios do autoritarismo as dimensões políticas e técnicas (transitando para o planejamento estratégico). Conforme Brasil (2004), um exemplo que exprime o escopo desse período é a ocorrência dos conselhos municipais. A autora, também, aponta uma perspectiva instigadora ao considerar a dimensão da racionalidade para além de uma visão instrumental e da possibilidade da ação comunicativa. Assim, cai o véu da racionalidade como representação, exclusiva, de uma perspectiva instrumental de meios e fins. Na contemporaneidade, se admitirmos a possibilidade de múltiplas racionalidades, como escopo do planejamento ao contrário de uma perspectiva sectária, vem à tona a dimensão da transposição de um tabu, a presença do especialista.

Contudo, é fundamental reafirmar o caráter da gestão democrática que, definitivamente, se insere na pauta da administração municipal pós-redemocratização do país. As transições do escopo do planejamento, nos anos 1990, para Maricato (1997) ocorrem no âmbito da escala (espacial e econômica). Ao citar Harvey, a autora admite o declínio do grande capital, do grande governo e do grande trabalho [dos sindicatos] (1991 apud MARICATO, 1997). Assim, pressupõe-se que o foco verte 
para a escala local. O contexto local expõe, na realidade brasileira, o embate entre o espaço privado e o espaço público. Para Brasil (2004), essa dimensão esbarra na caixa de pandora da propriedade. Assim, devemos admitir o direito de propriedade ou o direito à propriedade?

O direito de propriedade, no caso brasileiro, tem a ver com a produção do espaço pela sua dimensão geométrica (discurso comum e empírico), mas, principalmente, pelo acesso dos cidadãos ao solo. Assim, o que é designado, por alguns, como "desordem" ou "caos" é, evidentemente, a "periferia incógnita" ou a interface periurbana, isto é, a somatória dos "sistemas de desigualdades" e dos "sistemas de exclusões." Entretanto, a periferia, para além da geometrização, é uma construção dialética na práxis e, portanto, de nuances de uma transgressão inclusiva a capacidade da população de reagir (em alguns municípios brasileiros manifesta-se no centro), de algum modo, à exclusão compulsória do acesso ao solo.

Os municípios brasileiros, seja qual for a dimensão escalar, expõem os dilemas da desigualdade do acesso ao solo urbano ou a terra no caso do rural o que, entre outros problemas, não somente gera a exclusão como expõe a fragmentação do território na perspectiva dos bens e serviços públicos inclusive. Logo, a forma-conteúdo mais durável do processo de ocupação do território brasileiro, e portanto, de construção da nação, é o pacto de poder que engendrou/perenizou as estruturas altamente concentradoras de renda e riqueza e de impedimento do acesso à propriedade e à plena cidadania, dos direitos sociais, políticos e civis.

Conforme Lynch (2001), o discurso da sustentabilidade transplantado para a solução das desigualdades, principalmente a espacial, é o que poderíamos designar como "ambientalização" dos problemas sociais e setoriais, assim, ocorre a configuração do paradoxo. Para Lynch (2001), o problema vem à tona quando ocorre a redistribuição socioespacial dos fatores ambientais, isto é, a análise estabelecida para a tomada de decisão. Mais uma vez, o problema da escala se configura. Para a autora, "é provável que movimentos ambientais locais coloquem muito mais ênfase em questões urbanas do que na conservação em locais distantes" (2001, p. 66), Assim, o espaço rural como o regional não se coadunam na perspectiva socioespacial da noção de cidade no Brasil.

Costa coloca a seguinte problemática: “[...] como incorporar a intervenção planejada daquela conquistada por meio das práticas sociais?" (2000, p. 57). Ademais, como incorporar a sustentabilidade institucionalizada das ações e reflexões ao cotidiano? O que corrobora com a constatação de Lynch (2001) sobre a falta de informações e de monitoramento do território do município. 


\section{Considerações finais}

As análises estabelecidas ao longo do texto buscam demonstrar a importância do território do município para os processos de planejamento e gestão. $\mathrm{O}$ território, uma construção social, é capturado pelo conflagrar do jogo dos diversos interesses e escalas de poder. A apropriação da terra, do solo, no Brasil ainda é uma construção ortodoxa da propriedade como valor de troca para além da práxis do território. Seja como for, as demandas dos atores sociais no espaço urbano e no rural, inseridos na "comoditização" do mercado de terras, descortinam a necessidade de um planejamento inserido no cotidiano.

O termo cidade despontou no texto e teve ares de sinônimo de município, que foi proposital, uma vez que se inscreveu como uma paródia à urbanização do pensamento e se estende a todo o território. A cidade produz informações sobre si mesma, mas o território carece de assimilação pelo uso.

Portanto, o acesso aos bens e recursos públicos e os usos constitui a base dos dramas humanos nos municípios brasileiros onde a maximização dos lucros em relação ao mercado de terras, como direito, suplanta a função social da terra, principalmente, no espaço rural. No cerne dessa discussão, está a complexa relação jurídico-institucional que envolve a terra no Brasil. Há aspectos associados ao problema do ordenamento territorial, a regularização fundiária, a posse, a renda da terra e um distanciamento da função social, cujo Estatuto das Cidades tenta corrigir por intermédio de um mecanismo de planejamento, o plano diretor. Deveria ser o Estatuto do Território do Município. As formas de segregação socioespacial é um tema amálgama de vários elementos teóricos e políticas públicas além da própria inserção no contexto capitalista de parcela da população de excluídos.

Há, evidentemente, uma sensação perpétua de um xeque-mate (territorial no jogo de xadrez da organização do espaço) que em persa (shãh mãt) significa o rei está morto, ou simplesmente mate. É uma expressão usada no enxadrismo para designar o lance que põe fim à partida quando o rei atacado por uma ou mais peças adversárias não pode permanecer na casa em que está ou movimentar-se para outra ou ser defendido por outra peça. Se um jogador aplicar o xeque-mate e o adversário conseguir de algum modo escapar, quem aplicou o xeque-mate automaticamente perde o jogo.

Todavia a organização do espaço no território do município não é desencadeada tal qual a lógica de um jogo... ou será que sim? Seja como for, a espacialização das análises e o compartilhamento, com a sociedade, das regras e das normas do uso e ocupação do solo seria o primeiro pressuposto para o dimensionamento das ações e reflexões democráticas, cidadãs e solidárias. 


\title{
Chess space organization: the game and plan in the territories county
}

\begin{abstract}
This work is the result of a process of literature review involving theoretical and conceptual frameworks of urban and regional planning, organization of space and territory for a survey of the use and occupation of land in peri-urban interface of Foz do Iguaçu, PR which began in 2012 and was completed in 2014. The bibliography analyzed corresponds to the end of the 1970s until the 2000s whose works unveil the process of a post-military dictatorship conceptual transition in Brazil foreshadowing the search for a more democratic and critical approach towards the area. The axis of analysis is engaged in the design of a territorial citizenship that was called for by the 1988 Constitution subsidiary of the City Statute and, consequently, their planning tool the Master Plan. It can identify a set of actions taken and of conflicting decisions in the municipal territory of the composition. The article in an essay format aims to contribute to the theoretical analysis to demonstrate the political, social, spatial, methodological and economic variables that interrelate from space and expose the complexity of the municipality in dealing planning and management public. The text is composed of the introduction, the theoretical and conceptual framework in which we structure the problem of organization of space and finally the closing remarks.
\end{abstract}

Keywords: Organization of space. Spatial planning. Land use planning., Spatial scales.

\section{El ajedrez de la organización del espacio: el juego e el plan en el territorio del municipio}

\section{Resumen}

Este trabajo es el resultado de un proceso de revisión de la literatura que implica marcos teóricos y conceptuales de la planificación urbana y regional, la organización del espacio y el territorio de una encuesta sobre el uso y ocupación de la tierra en la interfaz periurbana de Foz do Iguaçu, PR, que se inició en 2012 y se terminó en 2014. La bibliografía analizada corresponde al final de la década de 1970 hasta la década de 2000, cuyas obras a conocer el proceso de transición de una dictadura conceptual post-militar en Brasil presagiando la búsqueda de un enfoque más democrático y crítico hacia la zona. El eje de análisis se dedica al diseño de una ciudadanía territorial que fue llamado por la Constitución filial del Estatuto de la Ciudad y, en consecuencia, su herramienta de planificación del Plan Maestro de 1988. Se puede identificar un conjunto de acciones llevadas a cabo y de decisiones contradictorias en el territorio municipal de la composición. El artículo en un formato de ensayo tiene como objetivo contribuir al análisis teórico para demostrar las variables políticas, sociales, espaciales, metodológicos y económicos que se interrelacionan desde el espacio y exponer la complejidad del municipio en la planificación y gestión de tratar público. El texto se compone de la introducción, el marco teórico y conceptual en el que estructuramos el problema organización Filigrana del espacio y, finalmente, las consideraciones finales.

Palabras-clave: Organización del espacio. La ordenación del territorio. La planificación del uso del suelo. Escalas espaciales. 


\section{Referências}

ARANTES, O. Cultura da cidade: animação sem frase. Cidadania. Revista do Patrimônio Histórico e Artístico Nacional, Brasília, n. 24, p. 229-241, 1996.

BAUDRILLARD, J. Simulacros e simulações. Lisboa: Relógio D’água, 1991.

BORJA, J.; CASTELLS, M. As cidades como atores políticos. Revista Novos Estudos, São Paulo, n. 45, p. 152-166, jul. 1996.

BRASIL. Lei no ${ }^{10}$. 257, de 10 de julho de 2001, Regulamenta os arts. 182 e 183 da Constituição Federal, estabelece diretrizes gerais da política urbana e dá outras providências. Estatuto da cidade. Disponível em: <http://www.planalto.gov.br/ccivil_03/leisLEIS_2001/L10257>. Acesso em: set. 2012.

BRASIL, F. P. D. Participação cidadã e reconfigurações nas políticas urbanas nos anos noventa. Revista Brasileira de Estudos Urbanos e Regionais, Recife, v. 6, n. 2, p. 35-52, 2004.

CAMARGO, C. P. F. et al. Crescimento e pobreza. São Paulo: Loyola, 1976.

CAMPOS F. C. M. Cidades brasileiras: seu controle ou caos. São Paulo: Nobel, 1989.

CARDOSO, A. L. Reforma urbana e planos diretores: avaliação da experiência recente. Cadernos IPPUR, Rio de Janeiro, a. XI, n. 1-2, p. 79-111, 1997.

CASTELLS, M.; BORJA, J. As cidades como atores políticos. Novos Estudos, São Paulo, 45, p. 152-166, jul. 1996.

CHOAY, F. O urbanismo. Utopias e realidades. Uma antologia. São Paulo: Perspectiva, 1979.

COSTA, G. M. Exclusão sócio-espacial na era urbano-industrial: uma introdução ao tema. In: ENCONTRO NACIONAL ANPUR, 7, Anais... Recife: MDU/UFPE, 1997. p. 1.421-1.436. v. 2.

COSTA, H. S. M. A reforma urbana e a busca da cidadania. Revista Indicador, Belo Horizonte: ALEMG, n. 27, p. 889-893, 1988.

Desenvolvimento urbano sustentável: uma contradição em termos? Revista Brasileira de Estudos Urbanos e Regionais, Recife, v. 2, n. 1, p. 55-71, mar. 2000.

GIDDENS, A. La constitution de la societé: elements de la théorie de la structuration. Paris: Presses Universitaires de France, 1987.

HARVEY, D. Espaços urbanos na "aldeia global": reflexões sobre a condição urbana no capitalismo do final do século XX. 1995. Transcrição de conferência proferida em Belo Horizonte. Mimeografado.

HARVEY, D. A condição pós-moderna. São Paulo: Loyola, 1991.

KOWARICK, L. A espoliação urbana. Rio de Janeiro: Paz e Terra, 1979.

LYNCH, B. D. Instituições internacionais para a proteção ambiental: suas implicações para a justiça ambiental em cidades latino-americanas. In: LYNCH, B. D.; ACSELRAD, H. A. (Org). A duração das cidades: sustentabilidade e risco nas políticas urbanas. Rio de Janeiro: DP\&A/ CREA-RJ, 2001.

MARICATO, E. As idéias fora do lugar e o lugar fora das idéias. In: MARICATO, E. et. al. A cidade do pensamento único: desmanchando consensos. Petrópolis: Vozes, 2000. 
Brasil 2000: qual planejamento urbano? Cadernos IPPUR, Rio de Janeiro, a. XI, n. 1-2, jan./dez. 1997.

Reforma urbana: limites e possibilidades - uma trajetória incompleta. In: MARICATO, E.; RIBEIRO, L. C. Q.; SANTOS JR, O. (Org). Globalização, fragmentação e reforma urbana: o futuro das cidades brasileiras na crise. Rio de Janeiro: Civilização Brasileira, 1994.

MONTE-MÓR, R. L. (Coord). Belo Horizonte: espaços e tempos em construção. Belo Horizonte: CEDEPLAR/PBH, 1994. p. 51-78.

Planejamento urbano no Brasil: emergência e consolidação. Etc... espaço, tempo e críti$c a$, Rio de Janeiro, v. 1, n. 1, p. 71-95, 2007.

OSTROM, E. et al. Governing the commons: the evolution of institutions for collective action. Cambridge: Indiana University, 1990.

QUEIROZ NETO, E. Organização sócio-espacial da terra no município de Oliveira, MG. 2011. Tese (Doutorado em Engenharia Agrícola) - Faculdade de Engenharia Agrícola, Universidade Estadual de Campinas, Campinas, 2011.

SANTOS, M. A natureza do espaço: técnica e tempo, razão e emoção. São Paulo: Edusp, 2002.

VAINER, C. As escalas do poder e o poder das escalas: o que pode o poder local? Cadernos IPPUR/ UFRJ, Rio de Janeiro, v. 9, p. 13-32, 2001-2/2002-1.

VEIGA, J. F. F. Território e desenvolvimento local. Oeiras: Celta, 2005. 